\title{
El lecho de Procusto o la convención sobre la competencia humana
}

\author{
Gloria Fariñas León
}

\section{Resumen}

El tema de las competencias ha ganado un gran espacio de debate acerca del desarrollo humano en la actualidad. Este ha reeditado su introducción por D. McClelland en la Psicología de los años 70 con nuevas acepciones y usos que no siempre se ajustan a las exigencias de desarrollo de la Psicología como ciencia y profesión y tampoco a las demandas del perfeccionamiento de la educación, uno de los terrenos de mayor aplicación del concepto. El presente trabajo se plantea un análisis al respecto y persigue esclarecer las implicaciones conceptuales y prácticas del concepto. Se arriba a la conclusión, con argumentos diversos, de que el concepto de competencia, por una parte, tiene un contenido convencional que obedece a fines utilitarios e instrumentales, y por otra, que su empleo retrasa el desarrollo de la Psicología como ciencia y profesión. No obstante, el concepto puede ser utilizado en determinadas circunstancias, que son esclarecidas también. Las fuentes utilizadas para el análisis fueron las observaciones de la autora y la literatura publicada que conducen, a la vez, a un análisis histórico y cultural del término. Palabras clave: Educación, competencias, desarrollo humano.

\section{O leito de Procusto ou a convenção da competência humana}

\section{Resumo}

A questão das competências ganhou um espaço importante nos debates atuais sobre o desenvolvimento humano. Estes permitiram reeditar o significado dado a este problema por D. McClelland na Psicologia dos anos setenta, com novos significados e usos que nem sempre estão em conformidade com as exigências do desenvolvimento da Psicologia como ciência e profissão, e também não se apresentam suficientes para responder às demandas da educação, como um dos maiores campos de aplicação do conceito. Este trabalho apresenta uma análise sobre o conceito em questão e procura esclarecer suas implicações do ponto de vista crítico. Argumentos diversos permitem concluir que o conceito de competência apresenta, por um lado possui um conteúdo convencional que atende a fins utilitários e pragmáticos e, por outro lado, seu uso atrasa o desenvolvimento da psicologia como ciência e como profissão. Contudo, tal conceito pode ser utilizado em determinadas circunstâncias que são esclarecidas neste artigo. As fontes utilizadas para a análise consistem nas observações da autora e na literatura publicada, o que conduzem por sua vez a uma análise histórica e cultural do conceito.

Palavras-chave: Educação, competências, desenvolvimento humano.

\section{The Procustean Bed or the Convention on Human Competence}

\begin{abstract}
The issue of competences has won today a major forum for discussion on human development. The theme was reissued by D. Mc Clelland in the Psychology of the seventy, with new meanings and uses that not always conform to the requirements of development of psychology as a science and profession. Neither it conforms to the demands of advanced education, one of the largest fields of application of concept.In this paper we analyse the issue, attempting to clarify theoretical and practical implications of the concept, from a critical standpoint. We found different arguments, about the the term competence: on the hand, it has a conventional content due to instrumental and utilitarian purposes, and on the other hand, its use delays the development of psychology as a science and profession. However, the concept can be used in certain circumstances, which are also clarified. The sources we use for analysis were the author's observations and the published literatura in the area, leading to a historical and cultural study of the concept.
\end{abstract}

Key words: Education, competences, human development. 


\section{Introducción al problema}

Adentrarse en los problemas del desarrollo humano en estos tiempos obliga, en cierto modo, al análisis sobre las competencias y la competitividad de las personas en las organizaciones, asimismo, a la consideración simultánea del progreso de la sociedad. A juzgar por la diversa literatura que se publica sobre esta cuestión a escala mundial, parece interesar a muchos investigadores y profesionales, especialmente a los profesores y, entre estos, a aquellos que trabajan en la educación superior. Se trata de una temática que exige una visión interdisciplinaria, para alcanzar una comprensión y explicación de profundidad a fin de ser aprovechada con plena conciencia -cosa que será objeto del presente trabajo-, no por obedecer a modas. Su definición en el campo de la Psicología, corresponde a McClelland, autor estadounidense de orientación conductista social. Los trabajos más conocidos de McClelland trataron lo que él llamó la motivación de logro y la sociedad de logro (1961); después el concepto de competencia (1973), muy coherente con ese tipo de motivación y sus atribuciones en el desenvolvimiento del ser humano. El concepto ${ }^{1}$, elaborado empíricamente partiendo de una amplia investigación acerca de las personas triunfadoras, denota que el éxito depende más de las características específicas (competencias) de estas, que de sus conocimientos, de su currículum o de los resultados que alcanzan en los tests de rendimiento.

Las competencias, son consideradas como conductas necesarias para el desempeño laboral exitoso (o sus indicadores observables), y fueron adoptadas por muchos departamentos de recursos humanos, desde hace algún tiempo, a modo de añadir valor a las empresas, y a la vez, como criterio para seleccionar el personal. También, durante los últimos quince años, las competencias se han convertido en patrón de medida de la calidad de la educación superior (igualmente de la educación general). Por su parte, los diccionarios refieren el término competencia en el lenguaje común, con un contenido bastante similar al asumido por las diferentes instituciones ${ }^{2}$.

El Diccionario de la Real Academia Española (DRAE, 2009) plantea en su primera acepción del concepto competencia: la oposición o rivalidad entre dos o más

\footnotetext{
1 No es justo olvidar en esta historia a autores como Chomsky (1972), quien utilizó el vocablo para referirse al dominio de la lengua; tampoco a Parsons, quien ya en 1949 elaboró un esquema conceptual que permitía estructurar las situaciones sociales, según una serie de variables dicotómicas. Una de ellas era el concepto de logro, orientado a la valoración de las personas por la obtención de resultados concretos; entre otros autores, que de cierto modo anticiparon el concepto. No obstante, en las publicaciones actuales no siempre refieren estas fuentes.

2 El Ministerio del Trabajo y Seguridad Social de Cuba las considera del siguiente modo:

un conjunto de conocimientos teóricos, habilidades, destrezas y actitudes que son aplicados por el trabajador en el desempeño de su ocupación o cargo en correspondencia con el principio de idoneidad demostrada y los requerimientos técnicos, productivos y de servicios, así como los de calidad, que se le exigen para el adecuado desenvolvimiento de sus funciones (1999, artículo3).
}

personas que aspiran a la misma cosa, al que agrega: situación entre empresas que rivalizan en un mercado ofreciendo o demandando el mismo producto. En una segunda acepción, considera: pericia, aptitud, idoneidad para hacer algo o para intervenir en un asunto determinado; igualmente señala: atribución legítima a un juez $u$ otra autoridad para el conocimiento o la resolución de un asunto. El diccionario portugués de Buarque de Holanda (2010), plantea las acepciones en orden inverso y señala como significado: capacidad, habilidad, aptitud, idoneidad. Se observa el vínculo entre competencia y competitividad, ambos tienen la misma raíz lingüística y en la práctica suelen considerarse juntos. Estos diccionarios sólo abordan los usos comunes, mientras que WIKIPEDIA (2010), amplía la acepción refiriéndola a distintos campos de trabajo, lo que considera una vulgarización del término inicial y cotidiano. Estos campos son: el Derecho, la Administración, la Contabilidad y la Psicología. En este último iguala las competencias a las habilidades (Fähigkeiten en alemán y abilities en inglés).

Canário (1999), refirió la existencia de ciento veintitrés significados del término, lo que destaca, por una parte, el interés en la expansión del concepto, y por otra, la imprecisión en su utilización. La definición del concepto de competencia, contiene, de forma alternativa o conjunta: habilidades, capacidades, actitudes, entre otras formas de la vida espiritual. Con cierta frecuencia aparece igualado al concepto de habilidad o al de capacidad. Es marcado el interés por su uso globalizado, a pesar de su variado empleo. No parece haber imperado hasta hoy, una torre de Babel tan animada, como la provocada por este tema. Cuando se utiliza el vocablo "macroconcepto" -aún con la borrosidad que admite la "Ciencia de la Complejidad" entre los límites de las diferentes construcciones teóricas-, la mayoría de los interesados sabe de qué se habla, en cambio, no ha ocurrido de modo similar con el de competencia.

Tiene valor agregar, que el término ha sido asumido por las organizaciones transnacionales encargadas de la evaluación de los servicios educacionales, lo que ha dado lugar a su difusión como requisito de análisis y de prácticas en este campo. Se trata de un concepto entronizado gracias a la globalización (Ramonet, 1998). La agencia europea Tuning (2007), entre otras, asume el concepto para apoyar las metodologías que emplea en la evaluación y acreditación de los planes y programas de estudio de las universidades iberoamericanas (Tuning $\mathrm{AL}$ ). También existen Tuning EUROPEA y Tuning EEUU. Esta organización defiende las competencias en el sentido de praxis, para lo que articula teoría y práctica, conocimientos científicos y saberes tácitos provenientes de las experiencias laborales y de vida. Tuning considera anacrónico el contenido de la definición como hacer focalizado en la realización de tareas (principalmente en los campos profesionales y académicos), y lo sustituye por la acción informada y orientada de manera reflexiva. También incluye en el concepto de competencia, diversas dimensiones de la personalidad, con independencia de su grado de esencialidad, mediación y jerarquía en el desarrollo 
del educando. Al respecto plantea la necesidad de "combinar dinámicamente conocimientos, habilidades, capacidades y valores (2007, p.5)" con la intención de convertirlo en una idea máximamente abarcadora, dada la complejidad creciente de la cultura y del desenvolvimiento humano.

Merece recordarse, que por detrás de estos planteamientos está el proceso de Bolonia, datado en los años noventa, y revitalizado sistemáticamente en el presente siglo, con las miras de crear un espacio europeo de enseñanza superior cohesionado, competitivo y atractivo para docentes y estudiantes de ese continente y de terceros países. Además, capaz de articular, de algún modo, a los actores entre sí (profesores, profesionales y empleadores) y de promover el empleo de los graduados, a la vez que favorecer la movilidad de estos. Debe reconocerse, que Tuning hizo una gran contribución al sistema europeo sobre la acumulación y transferencia de créditos. Sistema que encuentra en las competencias el denominador común, que sustenta las transacciones crediticias esperadas para captar los profesionales más competentes de diferentes países (Carrington \& Detragiache, 1999). Dicha organización subraya, que las competencias están asociadas a la competitividad. Entre las competencias genéricas estandarizadas para América Latina, dicha organización planteó las siguientes en el mismo documento referido anteriormente (no se abordan las competencias específicas, por no considerarse necesarias para el análisis):

1. Capacidad de abstracción, análisis y síntesis.

2. Capacidad de aplicar los conocimientos en la práctica.

3. Capacidad para organizar y planificar el tiempo.

4. Conocimientos sobre el área de estudio y la profesión.

5. Responsabilidad social y compromiso ciudadano.

6. Capacidad de comunicación oral y escrita en la propia lengua.

7. Capacidad de comunicación en un segundo idioma.

8. Habilidades en el uso de las tecnologías (información y comunicación).

9. Capacidad de investigación.

10. Capacidad de aprender y actualizarse permanentemente.

11. Habilidades para buscar, procesar y analizar información de fuentes diversas.

12. Capacidad crítica y autocrítica.

13. Capacidad para actuar en nuevas situaciones.

14. Capacidad creativa.

15. Capacidad para identificar, plantear y resolver problemas.

16. Capacidad para tomar decisiones.

17. Capacidad de trabajo en equipo.

18. Habilidades interpersonales.

19. Capacidad de motivar y conducir (liderazgo) hacia metas comunes. ambiente.

20. Compromiso con la preservación del medio

21. Compromiso con su medio socio-cultural.
22. Valoración y respeto por la diversidad y multiculturalidad.

23. Habilidad para trabajar en contextos internacionales.

24. Habilidad para trabajar en forma autónoma.

25. Capacidad para formular y gestionar proyectos.

26. Compromiso ético.

27. Compromiso con la calidad.

Al comparar los inventarios de las competencias genéricas elaborados por el proyecto europeo y por el latinoamericano, Tuning observó 22 competencias fácilmente comparables en ambos casos. El proyecto latinoamericano incorpora 3 competencias más: responsabilidad social y compromiso ciudadano, compromiso con la preservación del medio ambiente y compromiso con el medio sociocultural. No fueron consideradas 3 competencias del proyecto europeo en la versión latinoamericana: conocimiento de culturas y costumbres de otros países, iniciativa y espíritu emprendedor y motivación de logro.

En el ejemplo que expone Tuning, se iguala la competencia con el conocimiento, la habilidad, la capacidad, el compromiso o los valores, sin aclarar el vínculo intrínseco entre estos para designar distintos aspectos del desarrollo humano. Es el caso de las competencias 4, 5, 6, 8, 26, entre otras del inventario que repiten lo mismo. Tuning busca la integración en el sujeto, a través de cuatro factores. El primer factor, por ejemplo, abarca siete formas de capacidad, una de habilidad, una de conocimiento y el proceso de aprendizaje y similarmente en los siguientes factores.

\section{A favor y en contra de las competencias: ¿cuál es la historia?}

No se puede negar, la ocurrencia y desarrollo de las competencias. La permanencia o quiebra de las empresas depende en determinada medida de la competencia y de la competitividad de sus empleados y directivos. Por otra parte, qué sería de un nadador, de un pelotero, de un futbolista en certámenes nacionales o internacionales, sin ser competente y sin saber competir. El interés en estos casos es la lucha por la calidad y la preponderancia, lo que no significa que todo lo que tiene calidad tenga que haber sido motivado por la competitividad. Las competencias operan, luego existen. No obstante, su conceptuación exige un análisis más profundo, básicamente en cuanto a su origen, naturaleza, implicaciones éticas y necesidades de aplicación. Del mismo modo, la incidencia de su significado en el desarrollo de la ciencia, sobre todo en lo tocante a la concepción del desarrollo humano.

La aceptación tácita de los conceptos de competenciacompetitividad, ha ayudado a su establecimiento prioritario, como si fuera obvia su necesidad. Algunos autores han hablado del credo de las competencias. El origen del concepto, hay que buscarlo más allá de las definiciones: en el contexto socioeconómico de su aparición; especialmente 
en el caso de McClelland, ya que este trata de insertarlo en el terreno de la motivación y del desenvolvimiento humano, en una manera más amplia e influyente que Chomsky. El concepto de competencia está intrínsecamente ligado, por una parte, al de motivación de logro, y por otra, al de sociedad de logro -entendida como sociedad capitalista-, en cuyo seno, la competitividad tiene un peso decisivo. Se considera de este modo, que es la motivación de logro la que anima el desenvolvimiento socioeconómico de una nación determinada. Las épocas en que son acuñados estos conceptos en los campos de la psicología social y de la motivación (década de los sesenta y luego de los setenta) y que alcanzan mayor propagación máxime en la educación (desde los años noventa), coinciden con momentos de altas (1944-1973) y posibles peligros en la economía de los Estados Unidos (desde 1973 hasta la fecha).

Al hacer historia, debiera tenerse en cuenta que fue homo habilis la denominación dada por la antropología al ser humano que dominó, por primera vez, la elaboración de herramientas y el desarrollo de las habilidades para emplearlas, tanto en un plano material como espiritual (herramientas mentales). Esta denominación del ser humano como sujeto, tiene un valor histórico al mismo tiempo que cultural, principalmente para la ciencia. Su aceptación ha sido ya centenaria, y tiene mucho que ver con la conformación del concepto de sujeto en la historia. El concepto de competencia es propio de una época bastante posterior a la del homo habilis -la era del homo sapiens sapiens-y se utiliza para denotar una finalidad específica del comportamiento, que no necesariamente deviene general, ni en los sistemas capitalistas renovados en tiempos del neoliberalismo ${ }^{3}$.

El término de habilidad por su origen, historia $y$ extensión de contenido, incluye en sí mismo, el término de competencia ${ }^{4}$, que es particular de una etapa posterior de la evolución de la sociedad, aunque duradera. Si se hablara en un sentido estrictamente histórico y cultural, no pragmático, la competencia sería un caso particular de las habilidades (aquella movida básicamente por la motivación de logro en la búsqueda de la competitividad) y no a la inversa, como proponen sus divulgadores. Sin embargo, la competencia trata de erigirse en calidad de categoría única e universal, capaz de incluir otros conceptos (valores, conocimientos, habilidades, capacidades, etc.), aún sin considerar la naturaleza específica de cada uno ni establecer un orden jerárquico o histórico entre ellos, respecto a la orientación del desenvolvimiento humano en su carácter integral. Es el caso de Tuning, de amplia geopolítica. Allport (1983, p. 35), llamaba a este gusto ecléctico de mezclar ideas de distinta naturaleza y jerarquía, prácticas "de nido de corneja”, porque

3 Es natural que, el Banco Mundial (2002), esté interesado por el tema de las competencias en la educación, lo que por su contenido, merecería un análisis especial que no es posible hacer en esta oportunidad. Cito especialmente la dirigida a la educación superior, pero existen numerosas publicaciones de esta institución referidas a los distintos niveles de enseñanza.

4 Ocurre de manera similar con este concepto de habilidad, respecto al de competencia en la época del homo sapiens sapiens. estas aves suelen llevar a sus nidos, lo mismo una rama de árbol para alimentar a sus pichones, que un zapato. El término, por la variabilidad de su contenido, ajustable a los fines prácticos específicos, ha devenido una suerte de lecho de Procusto, en recordación al personaje de la mitología griega, que estiraba o serruchaba a los huéspedes que pernoctaban en su posada, para adaptarlos maliciosamente al tamaño de un lecho, que era secretamente regulable. Llama la atención que la idea de shopping center sigue la misma lógica, quiere decir, ser un agregado de cosas diversas, cuya razón de estar juntas no obedece a su naturaleza particular, vínculo esencial o jerárquico, sino a una necesidad práctica, en esta oportunidad: la necesidad de atraer los clientes al comercio, por la ventaja que ocasiona tener, en el mismo lugar: tiendas de vestuario, tiendas de alimentos, cine, teatro, cafeterías, restaurantes y otros lugares que servirían a diversos propósitos, lo que ahorraría tiempo a los clientes y conseguiría mayores dividendos para los dueños de los negocios. Raciocinio cómodo para la vida cotidiana, pero aplicado a la ciencia, banaliza la búsqueda de la esencia de las cosas que esta estudia.

Por otra parte, un inventario de competencias o de otras dimensiones -que siga la Lógica Formal como es el caso que se trata-, elude la visión profunda del comportamiento humano. Esto ha sido demostrado por diversos enfoques en la historia de la Psicología, que de alguna forma han buscado una concepción del ser humano, no basada en la integración estadística, sino en la integración de sentido o de sentido-significado de la vida como totalidad (Freud, Vygotski, Frankl, Allport, PichonRivière, entre otros, con independencia del nivel de acierto de cada uno de estos autores). El planteamiento de las competencias recuerda, por contraste, a autores como Catell (1972), cuya propuesta tuvo que recurrir al enfoque factorialista en la concepción de la personalidad (test $16 \mathrm{PF}$ de Catell). A través de la combinación de factores, este autor hizo abstracción de la dialéctica del desarrollo humano con su emergencia característica de formaciones psicológicas, de alta complejidad, condicionadas histórica y culturalmente. Si Tuning se refiriera en su conceptuación a los límites entre los perfiles profesionales, a las responsabilidades de cada persona, a lo que compete hacer o saber a cada cual, sería admisible, además, es uno de los usos comunes tradicionales. A juzgar por el tratamiento metodológico y práctico del concepto, los participantes de esta organización parecen pretender una teoría, sobre el funcionamiento del desarrollo humano y de la personalidad. O lo que es peor, eliminar el concepto de personalidad para sustituirlo por una combinatoria de factores.

Esta óptica del asunto aleja a la Psicología de las aspiraciones de la ciencia actual, al proponer un regreso al positivismo (Sousa, 1984), al reduccionismo, en fin, a la simplificación del conocimiento sobre el ser humano y a la reificación de las dinámicas personales e interpersonales. En consecuencia, la vuelta a los mitos (Lukács, 1967). El propio McClelland en el prólogo de su libro intitulado The Achieving Society (1961), alude a su "ingenuidad" respecto a los temas 
históricos, y hasta refiere una anécdota acerca del rechazo que recibió de un colega -a quien reconoce como eminente historiador de Harvard-, al saber este que McClelland había tratado de escapar de todos los cursos de historia.

Además, hay que preguntarse si el ser humano debe ser competente y competitivo en toda circunstancia. Igualmente, si todo lo bueno por producir tiene que ser resultado de la competitividad. Es importante reconocer el nexo esencial entre competencia y competitividad, ambos constituyen una unidad conceptual, como zona de desarrollo próximo-situación social del desarrollo. Otra pregunta no menos importante sería: ¿Cuál es entonces el ideal de ser humano explícito o implícito en el enfoque de las competencias?. Es difícil imaginarse a pintores y a compositores de música clásica como profesionales preferiblemente competentes y competitivos, lo que no quiere decir que no sean capaces de competir o de ser competentes en determinadas circunstancias. Resulta difícil también imaginarse a un empresario, de personalidad armónicamente integrada, como sujeto competente y competitivo en todas las esferas de la vida y en todo momento.

McClelland interpreta un estudio muy interesante realizado por Berlew (1956), sobre la obra de Homero y Hesíodo en la Grecia Antigua, considerados como historiadores exitosos porque consiguen poner en palabras, lo que está en el espíritu de todos (1961, p. 147). El estudio consistió en analizar en la obra de estos autores, el monto del contenido referente al logro. Este se puntuaba en dos niveles: a) siempre que uno de los personajes de la narración analizada esté empeñado en alguna actividad competitiva la cual vencer o actuar de modo igual o mejor que los otros, lo que es declarado explícitamente, como de importancia primordial. b) Cuando este tipo de actividad esté implícito en las narraciones de los personajes. McClelland comete aquí el mismo error de análisis señalado más arriba, porque absolutiza el contenido relacionado con lo competitivo en el texto, al no tener en cuenta el resto de la actividad cotidiana de los personajes y su engranaje con este. En otras palabras, se marginan contenidos que forman la totalidad del empleo del tiempo junto con la actividad competitiva. La competitividad ocupa todo el lugar. Tampoco es un hecho, el dominio absoluto de la motivación de logro. Además, esta forma de motivación no es necesariamente intrínseca. Es memorable la anécdota del poeta que rompía sus poesías una vez terminadas, porque su recreación espiritual radicaba en componerlas. Habría que cuestionarse la competencia de este sujeto, porque su placer provenía del proceso de la creación, no necesariamente del resultado. La subjetividad humana es muy compleja y alcanza dimensiones de plenitud, no reducibles a una tipología, por ejemplo: ganadores versus perdedores, competentes versus incompetentes. Tampoco a la de resultados versus procesos.

La Pedagogía, la Sociología y la Psicología tienen cierto retraso, con respecto a otras disciplinas, en la búsqueda de una concepción general del objeto de estudio para su análisis más cabal y profundo. La Psicología, al igual que las Ciencias Sociales en general, precisa explicaciones integradoras y profundas sobre el ser humano y su desenvolvimiento. La motivación de logro opera en conjunción con otras motivaciones, razón para no absolutizarla al evaluar una obra prominente. La pertinencia, relevancia y fama de una creación, no obedece obligatoriamente a la tiranía de la motivación de logro de su autor. Cuando se habla de las competencias, se invoca o se actualiza, de alguna forma, el concepto de sujeto racional cartesiano, poniendo en riesgo la aspiración de un ser humano más pleno y movido por el bien común (Hinkelammert, 2006).

Siempre cabría la pregunta acerca de cómo el gusto estético -y su refinamiento- pudiera ser considerado una competencia o alguno de sus componentes. Hasta ahora, esto parece no haber interesado mucho para los efectos actuales, aunque el pragmatismo encontraría alguna razón útil para hacerlo. Cuán difícil resulta imaginarse a cantautores tan relevantes para la música universal como Silvio Rodríguez y Chico Buarque de Holanda, preocupados con su competencia profesional y la competitividad de su obra, que va más allá de los intereses comerciales (Britto, 2005). El ideal sobre el "hombre de éxito", ha sido analizado desde diversas perspectivas, por la caricaturización que representa del "deber ser" en su consideración más humana. Chaplin (1936) expresó dramáticamente en el film Tiempos Modernos, los efectos enajenantes del taylorismo como práctica organizada del capitalismo en el plano laboral, que sirve de alerta ante sus sucesivos regresos, aunque con otros ropajes. El término competencia, se presenta ahora en una visión dulcificada, como si hubiera perdido su naturaleza intrínseca, más allá del taylorismo, del fordismo, en la época de la globalización más acentuada que haya vivido la humanidad.

Marcuse se opone a lo abstracto del pensamiento racionalista cartesiano, que entiende al individuo como sujeto ideal - el hombre unidimensional-, descartando el valor de lo corporal y de lo erótico imprescindibles para hablar del ser humano en lo cotidiano. Este autor remarca, al referirse al "extrañamiento bretchiano", la posibilidad que este ofrece para que el ser humano reflexione sobre el poder alienante de la sociedad capitalista de su época. Decía: La lucha [...] contra su absorción en la unidimensionalidad predominante, se muestra en los esfuerzos de la vanguardia por crear un distanciamiento que haría la verdad artística comunicable otra vez (1968, p. 96). El hombre unidimensional es víctima de su propia impotencia y de la opresión continua de un complejo método de dominación (Borón, 2003). No por gusto resulta absurda la idea del pintor competente o del directivo competente en todos los momentos de su vida cotidiana. Se está hablando de una misma persona que funciona como totalidad, lo que es propio de las personas sanas, no alienadas. Marcuse señala el distanciamiento del ser humano respecto al statu quo, a través del arte. El arte implica inspiración, espontaneidad, recreación espiritual, no obedece estrictamente a la estructura medio-fin programable, lo que es propio de la racionalidad cartesiana, de la racionalidad instrumental. Esta racionalidad es la que 
sustenta la teoría de las competencias, no es el caso del arte, a menos que responda a fines comerciales. Para él, es el arte, la salida del hombre unidimensional para vivir mejor.

La teoría de las competencias se ha tornado un retroceso en la ciencia. Como ya se apuntó, la vanguardia del pensamiento científico actual busca enfoques integradores y dialécticos. El análisis de cualquier inventario de comportamientos -es el caso Tuning-, se realiza a través de técnicas como los clusters, el análisis factorial y la varianza, en otras palabras, la lógica de las mediaciones entre estos comportamientos, no es analizada teniendo en cuenta el funcionamiento real de la vida del sujeto, sino desde una lógica externa, formal, impuesta por el análisis estadístico. Es cuestionable un enfoque que no contribuya al desarrollo teórico de la ciencia y que solo produzca resultados prácticos. Si los epígonos de las competencias pretenden mostrar que el término es mera convención de fines utilitarios, al menos debieran poner al descubierto la trama histórica y cultural en que se inserta su proposición. La presentación actual de sus ideas y prácticas, parece ser "incauta" ante la realidad de ambos condicionamientos.

No es ocioso mencionar que, en no pocas ocasiones, los especialistas que se dedican a la difusión de esta noción y a su práctica, desconocen las corrientes fenomenológicas de pensamiento -menos el enfoque materialista dialéctico, a no ser en su versión vulgar- porque siguen el pensamiento instrumentalista. Otro problema que se adiciona es que lo hacen con plena impunidad. El principio que prima es el utilitarista: si funciona, es cierto. La unidad estadística enfrentada a la unidad de sentido, o mejor dicho, la tercera persona enfrentada al sujeto o al yo. Es el sentido de la vida, el drama de la vida, lo que da unidad al desenvolvimiento humano (Frankl, 1991). Si se lleva el análisis al plano reduccionista, es la motivación de logro lo que da unidad al sujeto competente-competitivo o a sus competencias, no su análisis estadístico. Para poder ver el papel del sentido de la vida, hace falta tener una visión verdaderamente dialéctica del desarrollo de la personalidad, lo que no ocurre por una mera declaración de su aceptación conceptual. Vale recordar que no se ha escuchado otra cosa en los debates sobre las competencias, que los cálculos numéricos de una u otra índole. A lo que habría que agregar, que el lenguaje de las competencias se presta bastante bien para el ejercicio de la ingeniería del comportamiento, manera profesional de manipular a las personas o su control.

Una educación que pretenda el desarrollo integral del educando, corre el riesgo de desviar su rumbo si sigue esta concepción, ya que más tarde o más temprano acabará sometiéndose al dictado de la fragmentación del desarrollo humano y de los fines utilitaristas. Una educación sigue sin reparo este dictado, cuando en alguna medida es o ha sido instrumentalista. La teoría de las competencias plantea a la educación, una visión abstracta sobre el ser humano y su desarrollo, al presentar una imagen fraccionada de comportamientos al margen de su unidad de sentido -y del sujeto que lo cohesiona-, no calculable por métodos estadísticos sino por análisis basados en una lógica dialéctica. Esa teoría es igualmente abstracta, por la sobrevaloración de comportamientos (competencias), que forman parte de una unidad de análisis mayor, dado su abarque y esencialidad: el drama humano como totalidad (Politzer, s.f.). El burocratismo encuentra en esta concepción un apoyo a su forma de comprender el desenvolvimiento de las personas en la educación u otros ámbitos, gracias a la afinidad, de base mecanicista entre ambas perspectivas.

Si se analiza el concepto de competencia, a la luz del cálculo de los factores que presenta Tuning, la competencia es todo y parte al mismo tiempo, cosa que sería difícil de admitir aún en la lógica formal, que es la base del pensamiento de esta transnacional, como lo fue para McClelland, su impulsor más reconocido en el campo profesional. Además ¿por qué asumir un término tan cargado de una determinada ideología? ¿Por qué esta prepondera? ¿Se trata de desideologizar otras ideologías? La designación del ser humano como homo habilis, homo sapiens $u$ homo sapiens sapiens, nació bastante al margen de este debate entre ideologías para referir un hecho histórico y cultural constitutivo de lo que es el ser humano hoy. A la luz de estas designaciones, el concepto de habilidad es más inclusivo o menos discriminador. Hasta los propios usuarios del término competencia igualan ambos con frecuencia. Los conceptos de ser humano, persona, sujeto y personalidad, educando, profesor, entre otros, son igualmente abarcadores y antecedieron también al concepto de competencia, en la historia de las ciencias sociales. Es posible que los autores del término y sus difusores, planteen la necesidad de que la antropología registre la aparición del "homo compĕtentis". O tal vez, rechacen el concepto de personalidad porque el examen factorialista del ser humano les impide ver su valor. Corresponde decir entonces, que las hojas de los árboles no dejan ver el bosque.

\section{Acerca del lenguaje de la ciencia}

El taylorismo y el conductismo fueron contemporáneos, y no por casualidad tuvieron un mismo fundamento: el escenario socioeconómico de la primera mitad del siglo $\mathrm{XX}$ en Estados Unidos. Ambos perseguían la eficiencia del comportamiento humano para el éxito de la empresa capitalista. El taylorismo consiguió un método de organización del trabajo que permitía el aumento de la productividad mediante la máxima división de funciones, la especialización del trabajador y el control estricto del tiempo necesario para cada tarea. El conductismo demostró experimentalmente, lo que pretendía el taylorismo en la práctica social. Los conductistas han sido perspicaces, porque plantearon a través de la historia de la Psicología, diversas formas válidas para el aprovechamiento del potencial pasivo de la actividad humana (la manipulación del comportamiento), y ante la crítica por la desconsideración del potencial humano activo, encontraron pertinazmente formas tan lineales y mecánicas como las ya conseguidas (condicionamiento operante, variables intermediarias, necesidades de logro, motivación de logro, etc.). Las 
aplicaciones del conductismo son muy conocidas en el campo de la Psicología, la Pedagogía y la Sociología. Es el caso de la Learning Village (Hren, 1978) y de Los Horcones tratada en Walden II por Skinner (1973). Al igual que muchos sistemas de pensamiento social experimental, el conductismo autocumplió su profecía, porque realizó sus fines y asumió este hecho como demostración válida de su ideario, sin someterlo a la crítica ética ni contrastarlo con otras ópticas sobre el desenvolvimiento del ser humano.

El conductismo ha sido uno de los enfoques más influyentes en el pensamiento de las ciencias sociales y las ciencias económicas del siglo $\mathrm{XX}$, lo que persiste en el presente siglo. Ha sobrevivido, entre otras razones, por su capacidad mimética o de camuflaje. Esta capacidad ha estado a tono con la crítica de sus opositores, sin embargo, no para cambiar su lógica emblemática. Así surgieron nuevas formas de conductismo que preservaron su esencia nata, asumiendo solo formalmente las críticas cruciales de los otros enfoques. Por ejemplo, el Neoconductismo, el Conductismo Social, el Cognitivismo, etc. De manera similar, han aparecido más recientemente diversas variantes específicas de este mismo raciocinio ("miniteorías" en términos allportianos): las inteligencias múltiples y la inteligencia emocional, que intentan disimular su naturaleza originaria, al punto de parecer teorías humanistas. Otra reedición del conductismo ha sido la concepción de las competencias y la competitividad propuesta por Tuning, analizada en este artículo.

El conductismo sigue presente, entre otras razones, gracias a que ha asumido el lenguaje de los enfoques que lo han desacreditado. Así existen teorías conductistas y cognitivistas de la personalidad, pues es sabido que los humanistas norteamericanos, que fundamentaron sus concepciones en enfoques fenomenológicos, le dieron una batida importante. Pero no es propósito del presente trabajo echar por tierra, lo que representó el Conductismo para el establecimiento de la Psicología como ciencia positiva a principios del siglo XX, el problema es otro: su ideal de ser humano y la forma en que pretende establecer determinados cánones, sobre todo para la educación. Todas las versiones conductistas, ponen en riesgo la visión integral y dinámica del drama humano o la mecanizan. Por suerte, la obra de tantos escritores como Martí, Balzac, Dostoiévsky, hacen fehaciente la realidad, de que es el sentido de la vida de un ser humano, enclavado en una cultura y en un periodo histórico determinado, lo que propicia su unidad interna como sujeto o su enajenación cuando se trata de su pérdida, que en buena medida es fragmentación, esquizofrenización.

Se ha dicho, y es cierto, que los seres humanos se parecen más a los cuentos que a las cuentas, aunque ellos también inventaron estas últimas. Los valores, los intereses, el gusto, las preferencias, la creatividad, entre otros procesos y fenómenos de la personalidad, no obedecen a programas de entrenamiento. Ellos constituyen un tejido de mediaciones bien complejo, no susceptible de inventariarse, por lo que escapan de alguna manera de la manipulación del otro (padre o madre, profesores, jefes, etc.). El cálculo estadístico, utilizados para analizar las competencias (las partes) es desigual al sujeto y a la personalidad (el todo) y a su narrativa. En el inventario de las competencias, subyace la creencia de que las dinámicas psicológicas operan de manera lineal por asociación (combinatoria). Es el eterno problema del reduccionismo, que parece no resolverse, sino reeditarse una y otra vez.

El conductismo ha adoptado sistemáticamente nuevas formas para sobrevivir, lo que es lógico porque el capitalismo perdura. De esta manera, los conductistas han asimilado el discurso histórico culturalista, para adaptarlo a su esquema racional; manifestación de mimetismo, que significa la deformación del pensamiento de su opositor. Lo hacen de palabra, no de hecho (Fariñas, 2006). Así han recortado la comprensión del significado de ideas tan importantes como las de zona de desarrollo próximo y de situación social del desarrollo, en este último caso reduciéndolo a su mínima consideración, y con esto, han adoptado formalmente el ideario original. Es la lógica del utilitarismo, la que se impone: tomar lo que sirve a los fines prácticos trazados, no cambiar los fines, que es una de las cosas más criticadas. Lógica también presente en el uso del término competencia. El enfoque histórico cultural demostró la necesidad de la integración de todo su aparato conceptual para conseguir validez en cuanto a la comprensión y explicación del desarrollo humano, con un método más cabal, dialéctico y profundo, cosa no pretendida por el modelo conductista.

Es además, el gusto por las palabras, la confianza en ellas como sustitutas de la realidad. Porque se dice algo, ya es, ya existe. Porque se dice, todos lo creen. Lo que sucede es que el camuflaje mencionado solo puede lograr cierta efectividad en el campo del discurso, teniendo en cuenta que siempre hay personas dispuestas a creer en las apariencias. El discurso ha sido aquilatado en demasía por el Posmodernismo (Fariñas, 2006). La promesa no siempre conlleva su cumplimiento, además todo vale. Este camuflaje lingüístico opera como si la comunicación del ser humano pudiera sustituir su actividad, como si el hecho de decirlo o escribirlo en un inventario, lo hiciera operar efectivamente en la realidad. Claro está, es posible pretender la educación de la personalidad desde posiciones conductistas, lo que significaría esquematizar su comprensión. El neoliberalismo necesita un fundamento, de otra manera no operaría de manera eficiente a escala social. Estas formas de operar son las competencias, compatibles con el núcleo ideológico del sistema en que se originó esta concepción en todas sus versiones. Las competencias responden al sistema de pensamiento eficientista sobre el comportamiento del ser humano y su desarrollo.

\section{Los compromisos en la burocratización de la educación}

Los directivos de la educación superior, presionados por las transnacionales (Tuning, etc.) se empeñan en la 
instauración de diversas modalidades de la universidadempresa (unas son más absolutistas, mientras que otras actúan con cierta reserva logrando ser más sutiles o flexibles). El énfasis en estos casos se dirige a la productividad de las universidades y sus centros a cargo (de investigación, etc.). Productividad que se convierte en productivismo al plantearse, por ejemplo: estándares a alcanzar en detrimento de las consideraciones casuísticas o emergentes del proceso de enseñanza; rutinas fijas en la enseñanza que permiten lograr los "resultados esperados", al mismo tiempo que violentan la dialéctica natural del aprendizaje en el estudiante; controles sistemáticos hasta el último eslabón del proceso, que pudieran afectar el curso de la dinámica creativa de la educación e invadir la organización del tiempo de profesores y estudiantes; ponderación de las categorías evaluativas que buscan un rasero para la comparación entre instituciones o personas, que necesitan reconocer su originalidad. Igualmente destacable es la intensificación del trabajo, por ejemplo, del profesor sometido a los estándares de horas, cantidades de resultados (artículos, patentes, etc.). en fin, toda una industria "fordista", para la cual, las competencias constituyen su mejor dictado. Las competencias son congruentes con la preponderancia de la motivación de logro en la sociedad de logro, nada más parecido a lo que se señaló sobre la universidad-empresa (de Sousa, 2006); ellas están concebidas en calidad de unidades programables y medibles, también susceptibles de diversos análisis estadísticos acostumbrados en estos casos. Ahora bien, si no es necesario desterrar el término competencia, tampoco hay que hacerlo con el análisis estadístico. Simplemente debe discernirse, cuándo estos son necesarios verdaderamente y cuándo alteran la naturaleza intrínseca de los fenómenos y procesos a los que se refieren, con el objetivo pragmático de informar lo demandado.

La universidad, si se precia de ser una institución de pensamiento, debe dar lugar a debates que amplíen la mirada sobre la realidad, y no casarse con un modo de pensamiento único, sobre todo si este tiende a la estandarización de procesos cuya esencia es heterogénea, única e irrepetible (la identidad y el desarrollo, ya sea personal o grupal, disciplinario, sectorial, institucional, etc.). Este tipo de concepción reifica las relaciones humanas, a la vez que da lugar a métodos de dominación (Kohan, 2003). El ideario humanista cubano concibe el desarrollo del estudiante -a través de la educación- como un sujeto culto, con una vida íntima plena, a la vez que comprometido socialmente, crítico y transformador, lo que quedó reflejado en su Reforma Universitaria de 1962 (Consejo de Universidades).

\section{El rescate de la competencia a toda costa}

No ha faltado quien haya tratado de fundamentar el uso de la teoría de las competencias, a partir de otras con pretensiones más elevadas, no solo prácticas. Y para logarlo ha tenido que repetir el mismo procedimiento señalado en el epígrafe anterior: la adopción del discurso opositor deformándolo en su naturaleza. Esto significa, por una parte, el mimetismo con el nuevo discurso, y por otra, el escamoteo de las conquistas de la perspectiva asumida, con su respectiva deformación. Un enfoque teórico que resulta atractivo para esos fines, es el histórico cultural, porque este ofrece soluciones a las insuficiencias tratadas aquí.

Una primera variante pudiera ser la asimilación del concepto de competencia, según la definición dada por Tuning (o por cualquier especialista de las competencias), dentro del enfoque histórico culturalista. Entonces habría que preguntar: ¿por qué asumir el término competencia? ¿Para sustituir sus términos tradicionales? ¿A qué responde esta "modernización"? o tal vez es mejor decir posmodernización, dado el valor que se le atribuye al vocablo como convención susceptible de incluir contenido de diversa índole, siempre que sea útil para los fines de sus usuarios (vale todo). El argumento de esta variante es el afán de que el concepto de competencia domine, en la concepción de la educación, de las organizaciones, etc., con un fundamento teórico que históricamente ha tenido prestigio en el abordaje de las problemáticas del desarrollo humano. Muchos educadores miran con buenos ojos al enfoque histórico cultural, por la posibilidad que este ofrece para superar los problemas de la educación actual. De modo que si se coloca el concepto dentro de esta visión teórica, es posible que gane crédito. La segunda variante de solución, con similares intenciones, es incorporar aspectos del enfoque histórico cultural o la totalidad de este, a la concepción de Tuning (o de otros que estudian las competencias); aunque cualquier forma de esta segunda variante es más difícil de llevar a cabo. La cuestión es, que a causa del mimetismo y del escamoteo de visiones ajenas, se puede esperar cualquier proposición, aunque las consideraciones que sigan en el raciocinio den elementos suficientes sobre la incompatibilidad de la pretendida simbiosis, que no llegaría a ser otra cosa que superposición parasitaria. Por consiguiente, es conveniente seguirle la pista a las consecuencias, que tendría esa asociación y sus opciones básicas de camuflaje.

No es casual, que los partidarios de estas ideas propongan también el cambio del nombre original del enfoque, al menos, el más reconocido históricamente, por el de Histórico Social y otras combinaciones ${ }^{5}$. En algunas de las opciones se elimina el peso de lo cultural, quizá por la incomprensión de que: "...sin hombres no hay cultura por cierto, pero igualmente, y esto es más significativo, sin cultura no hay hombres (Geertz, 2003, p. 72). Al eliminarse la denominación "cultural", sería posible obviar la crítica a la cultura, especialmente a la cultura dominante (Lukács, 1967). Y liberar la cultura de culpa, permitiría depositar la culpa en el ser humano. Es decir, el ser humano es competitivo por naturaleza, todo aquel que no sepa competir es culpable de su fracaso. Para competir y ser competitivo, hay que tener cierta formación cultural. Y esta es precisamente una de las

5 Las expresiones más largas tienden a rechazarse por un problema de economía en el lenguaje o por un concepto estético. Baste recordar el término biopsicosocial, que desconsidera que lo psicológico incluye lo biológico y lo social. 
cosas que no convendría ser tenida en cuenta en el análisis. La división entre personas exitosas y fracasadas caería entonces en el terreno de la oportunidad, del acceso real al conocimiento que hace falta para desarrollarse como ser humano, en este caso competitivo. La cultura...transforma los dotes naturales en correspondencia con los fines del hombre, decía L. S. Vygotski (1987, p. 163). Lo erróneo en estos casos sería concebir instrumentalmente la cultura, cosa propia de su interpretación comercial; igualmente, reafirmar el gusto por la cultura "light", propia del facilismo de la educación en estos tiempos de las competencias y del Hombre Unidimensional.

Se llama la atención al respecto, porque el enfoque histórico cultural ha tenido diversas interpretaciones positivistas a lo largo de su historia, luego es posible su aceptación dentro de la concepción de las competencias, lo que solo de manera formal, descartando su ética - ¿y por qué no también su estética?- o asumiéndola en apariencias. Hay que saber distinguir, cuando se habla en un auténtico lenguaje culturalista y cuando se habla en un lenguaje "culturalista" instrumental (Bruner, 1997). El primero es a la vez, histórico, cosa que no interesa mucho a la cultura empresarial, que reduce la trama universal de la cultura a los aspectos utilitarios. El establecimiento de la unidad competenciacompetitividad, como categoría que fundamenta la educación en el contexto actual de la globalización, persigue una cultura parcializada: la cultura empresarial, separada del complejo patrimonio cultural de la Humanidad, en su sentido amplio. Integrar la categoría "competencia-competitividad" a ese panorama cultural, implica de algún modo, el análisis crítico en el sentido que apuntó Lukács, (1967). Lo que se elige en cambio, es decretar su uso.

El planteamiento del enfoque vygotskiano, como histórico social, pudiera servir a los fines de posiciones no progresistas. Por ejemplo, aquellas que culpan a los marginales de su situación social, como si en la sociedad actual no hubiera diferencias de oportunidades en el acceso a la cultura. El condicionante en este caso no es la sociabilidad (o la no sociabilidad), sino la cultura o la incultura. "Ser culto es el único modo de ser libre (...)", decía Martí (1963, p.289). La sociabilidad no se conquista, se nace con ella, es inalienable. Es la oportunidad de acceder a la cultura, a la educación durante toda la vida, la que permite sostenidamente el desarrollo del ser social. La división de los sujetos en competentes e incompetentes, exitosos y fracasados, tiene en su base, aunque de modo tácito, la desesperanza de "llegar a ser alguien". El análisis histórico y cultural del desarrollo humano muestra el modo en que el sujeto obra su desarrollo y amplía sus potencialidades, en un proceso eminentemente solidario.

No obstante, quedan por ver nuevos mimetismos y escamoteos en ese proceso de adaptación del Conductismo, en su versión de las competencias. Ellos responderán a necesidades utilitarias, que dependen de las necesidades particulares de los especialistas que los pongan en práctica. La torre de Babel promete continuar, ahora con nuevas bases.

\section{Referencias}

Berlew, D. (1956). The achievement motive and the growth of Greek Civilization. Em McClelland, D. Em The Achieving Society. Princeton: Van Nostrand.

Borón, A. (2003). Tras el búho de Minerva (mercado contra democracia en el capitalismo de fin de siglo). La Habana: Ciencias Sociales.

Britto, L. (2005). El imperio contracultural: del rock a la posmodernidad. La Habana: Arte y Literatura.

Bruner, J. (1997). La educación, puerta de la cultura. Madrid: Visor.

Buarque de Holanda, A. (Ed.). (2010). Dicionario Aurélio da Língua Portuguesa (5a ed.). Curitiba: Editora Positivo.

Canário, R. (1999). Educação de Adultos. Um Campo e uma Problemática. Lisboa: Educa.

Carrington, W., \& Detragiache, E. (1999). How Extensive is the Brain Drain?. Finance \& Development, (36).

Chaplin, C. (Productor/Escritor/Director). (1936). Modern Times [Película]. Estados Unidos: United Artists.

Chomsky, N. (1972). Lingüística cartesiana. Madrid: Gredos.

Competência. (2010) Wikipédia, a enciclopédia livre. Recuperado: 11 ago 2011. Disponível: http://pt.wikipedia.org/w/index. php?title=Compet $\%$ C3\%A Ancia\&oldid=22952859

Cuba. (1962). Reforma Universitaria del 10 de enero de 1962. La Habana: Universidad de La Habana.

Cuba. (1999). Resolución 21. Ministerio del Trabajo y Seguridad Social del $1^{\circ}$ de junio de 1999. Disponível: http://www.cubaindustria. cu/contadoronline/ Perfeccionamiento\%20 Empresarial/ Legislaci\%C3\%B3n/RES-MTSS-21-1999.htm\#C01

De Sousa Santos, B. (2006). La Universidad en el siglo XXI. La Habana: Casa de las Américas.

Real Academia Española. (2008). Diccionario de la lengua española. Microsoft Student con Encarta Premium [DVD]. Washington: Autor.

Fariñas, G. (2006). Psicología, educación y sociedad. La Habana: Félix Varela

Frankl, V. (1991). El hombre en busca de sentido. Barcelona: Herder.

Geertz, C. (2003). Impacto del concepto de cultura em el concepto de hombre, En Colectivo de autores (Ed.). Selección de Lecturas de Sociología (p. 72). La Habana: Félix Varela.

Hinkelammert, F.J. (2006). El sujeto y la ley. El retorno del sujeto reprimido. La Habana: Caminos. 
Hren, C. (1978). "La escuela primaria de la Learning Village". En R. Ulrich y cols. (Orgs.), Control de la conducta humana. (Vol. 3, pp. 164-175). México, Trillas.

Kohan, N. (2003). Marx en su (Tercer) Mundo. Hacia uma socialismo no colonizado. La Habana: Ciencias Sociales.

Lukács, G. (1967). Existencialismo o Marxismo. Sao Paulo: Senzala.

Marcuse, H. (1968). El hombre unidimensional. Barcelona: Ariel.

Martí, J. (1963). Nuestra América (Tomo 8). La Habana: Editorial Nacional de Cuba.

McClelland, D. (1961). The Achieving Society. Princeton: Van Nostrand.

McClelland, D. (1973). Testing for Competence Rather Than for Intelligence. American Psychologist, (28), 1-14.

Parsons, T. (1937). The Structure of Social Action. New York: MacGraw,
Politzer, G. (s/f). Crítica dos fundamentos da Psicologia. Lisboa: Presença.

Ramonet, I. (1998). O Pensamento Único e os Regimes Globalitários. Em J. L. Fiori y cols. (Org.), Globalização: o fato e o mito (pp. 54 75). Rio de Janeiro: EDUERJ

Sousa Patto, M. H. S. (1984). Psicologia e Ideologia: uma introdução crítica à Psicologia escolar. São Paulo: T. A. Queiroz.

Skinner, B.F. (1968). Walden II: una sociedad del futuro. Madrid: Orbis, S.A.

Tuning (2007). Reflexiones y perspectivas de la Educación Superior en América Latina Informe Final. Bilbao: Universidad de Deusto.

Vygotski, L. S. (1987). Historia del desarrollo de las funciones psíquicas superiores. La Habana: Científico Técnica.

World Bank (2002). Constructing Knowledge Societies: New Challenges for Tertiary Education. Washington D.C.: The World Bank. 